\title{
Structure and Composition of Ba-W-Ti-O Ceramics Interface Regions Formed at Ultrasonic Vibration
}

\author{
O. Karban, ${ }^{1}$ O. Kanunnikova, ${ }^{1}$ E. Khazanov, ${ }^{2}$ E. Salamatov, ${ }^{1}$ O. Khasanov, $^{3}$ and A. Taranov $^{2}$ \\ ${ }^{1}$ Physical-Technical Institute UB RAS, 132 Kirov Straße, Izhevsk 426000, Russia \\ ${ }^{2}$ Kotelnikov Institute of Radio Engineering and Electronics, RAS, 11 Mokhovaya Straße, Korp. 7, Moscow 125009, Russia \\ ${ }^{3}$ Scientific-Educational Nano-Center, Tomsk Polytechnic University, 30 Lenin Avenue, Tomsk 634050, Russia
}

Correspondence should be addressed to O. Karban, ocsa123@yahoo.com

Received 2 April 2012; Accepted 29 April 2012

Academic Editors: C. Angeles-Chavez, G. Speranza, and V. Yamakov

Copyright (C) 2012 O. Karban et al. This is an open access article distributed under the Creative Commons Attribution License, which permits unrestricted use, distribution, and reproduction in any medium, provided the original work is properly cited.

\begin{abstract}
The study of Ba-W-Ti-O ceramics has shown that the structure and composition of their interface regions differ from those in the grain bulk owing to the diffusion of tungsten atoms to the grain surface during sintering. They are determined by the conditions of compacting of dry nanopowders (compaction pressure and power of ultrasonic action) and vary in a nonmonotonic way. Increasing the pressure during dry static compacting and exposure to ultrasound result in the formation of a complex structure of fragments and boundaries between them, increasing the acoustic density and decreasing the intergranular boundary thickness. This affects the travel time of the phonon pulse through the sample, which allows one to determine the density and thickness of the grain boundaries by the method of phonon spectroscopy.
\end{abstract}

\section{Introduction}

The functional characteristics of the segnetoelectrical ceramics based on $\mathrm{BaTiO}_{3}-\mathrm{WTiO}_{3}$ depend on the structure which in turn depends on the conditions of manufacture. The physical characteristics of barium-titanate ceramics were shown to be size dependent [1-4], and the $\mathrm{Ba} / \mathrm{Ti}$ ratio was found to determine the grain growth mechanism $[5,6]$. At the same time, as was shown in [7-9], the relation between the elements in the ceramic interface regions may substantially differ from that in the bulk, which can result in both phase transformation and new phase formation. There may form, for example, a cubic-phase layer in the interface regions of polycrystalline tetragonal ceramics $\mathrm{BaTiO}_{3}$ [10], a $\mathrm{BaCO}_{3}$ phase as a result of interaction with atmospheric $\mathrm{CO}_{2}$ on heating [11], and a glass phase in the interface areas of segnetoelectrical ceramics [12]. The changes in structure and phase composition occurring during sintering depend on both rheological heredity and compacting parameters.

The most used technologies are based on various powder consolidation techniques: uniaxial static pressing [12], dynamical pressing, and hydrostatic pressing which, as a rule, lead to large density gradients in compacts of complex shape. This may cause deformation or crack initiation during sintering, and it is impossible to reduce mechanical stresses in the compacted object and minimize the inhomogeneous deformation during subsequent sintering of such ceramic compacts without plasticizers. However, the use of plasticizers and binding agents is not always possible as it may cause the material contamination and the increase of residual porosity. The density and stress distribution in the bulk of compacts depend on the conditions of wall friction on compacting.

As known, the exposure to ultrasound (US) during dry uniaxial compacting reduces the interparticle friction and favors uniform close particle packing in compacts [13]. In this work we have studied the effect of the ultrasound power applied during powder compacting on physical properties of ceramic compacts.

\section{Experimental}

The nanosized powders of $\mathrm{BaTiO}_{3}-\mathrm{WTiO}_{3}$ composition with an average particle size of $50 \mathrm{~nm}$ obtained by the sol-gel method were compacted by uniaxial dry pressing under US 


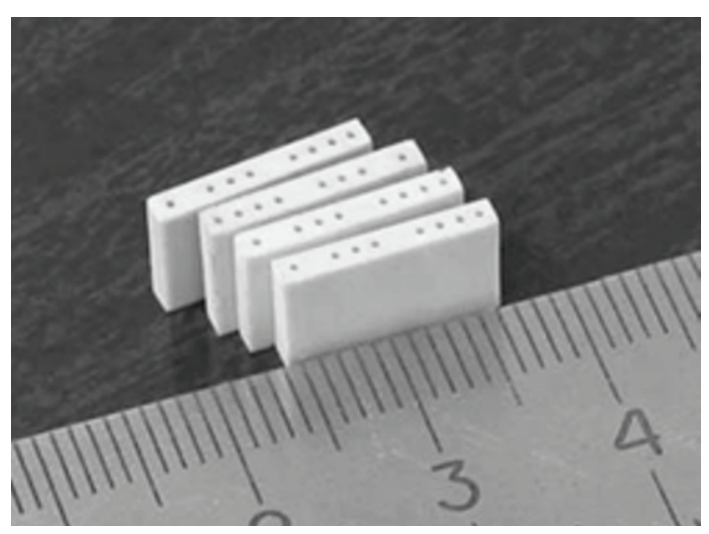

FIgUre 1: Ceramic cases of microwave amalgamators from $\mathrm{BaTiO}_{3}$ $\mathrm{WTiO}_{3}$ nanopowders.

action (the amplitude of $5 \div 10 \mu \mathrm{m}$, the frequency of 20 $22 \mathrm{kHz}$ ). The scheme and characteristics of the equipment for obtaining samples are described in [13]. The compacting parameters (compacting pressure and US power) are listed in Table 1. The ceramics were sintered at a temperature of $1623 \mathrm{~K}$ for 3 hours. The sintered specimens had the shape of a parallelepiped $2 \times 14 \times 8 \mathrm{~mm}$ in size having 8 holes of diameter $0.6 \mathrm{~mm}$ with a positioning precision of \pm 5 microns (Figure 1). The same tolerance value was required for the specimen dimensions.

The X-ray studies were performed with a DRON-3 diffractometer in $\mathrm{CuK}_{\alpha}$ monochromatic radiation. The images of the specimen surface chips were obtained with a scanning electron microscope (SEM) Philips XL30 and a scanning probe microscope Solver P47. The chemical composition was analyzed by the X-ray photoelectron spectroscopy (XPS) using modified ES-2401 spectrometer. The spectra were excited by the $\mathrm{MgK}_{\alpha}$ radiation. The vacuum in the analyzer chamber was $5 \cdot 10^{-6} \mathrm{~Pa}$. The spectra were calibrated against the $\mathrm{C} 1 s$-line $\left(E_{b}=285.0 \mathrm{eV}\right)$ of the adsorbed hydrocarbon layer [14]. The mathematical treatment of the spectra was carried out by a technique based on the Fourier analysis with an improved convergence procedure [15]. The specimens for XPS analysis were prepared as chips.

The structure of the ceramics interface regions and their specimen-average characteristics were investigated by the heat pulse method [16]. This approach is based on the analysis of the weakly nonequilibrium phonon (NP) transport in the specimen studied at helium temperatures when the NP wavelength $\lambda$ is less than the mean grain size $R$ but comparable to the intergranular interface thickness. The method and the model used as well as the peculiarities of the data processing are detailed in $[17,18]$. In this work we analyzed the propagation of the flow of weakly nonequilibrium thermal phonons generated by pulse heating of a metal (gold) film deposited on a face of the specimen under study. The phonon nonequilibrium pulse transmitted through the imperfect specimen was registered on the opposite side by a broadband detector (bolometer) based on a superconducting thin film. The measurements were performed at helium temperatures at which inelastic phonon-phonon processes are unlikely. The thermostat temperature $T_{0}$ could be modified by means of He vapor evacuation in the $1.5-3.8 \mathrm{~K}$ interval. The bolometer operating point was shifted in temperature by the field of a superconducting magnet situated in the immediate vicinity of the bolometer. The power generated in the NP-injector film $(\mathrm{Au})$ amounted to $10^{-2} \div 10^{-1} \mathrm{~W} / \mathrm{mm}^{2}$ (the pulse duration was $\leq 100 \mathrm{~ns}$ ), the film being heated to a temperature $T_{h}$ such that $\triangle T=T_{h}-T_{0} \ll T_{0}$. This allowed us to assume the Planck distribution of NP phonons to have the thermostat temperature. The measurements performed at different $T_{0}$ permitted to obtain the temperature characteristics of subterahertz NP scattering.

\section{Results and Discussion}

The density of the sintered specimens was $4.43-4.52 \mathrm{~g} / \mathrm{cm}^{3}$ (Table 1). With increasing compacting pressure, the specimen density grows reaching its maximum at $P=874.4 \mathrm{MPa}$ and $W=1.5 \mathrm{KW}$. With further increase in compacting pressure, the sintered-specimen density decreases in contrast to the compacts whose density increases monotonically with pressure [19].

The diffractograms of sintered $\mathrm{Ba}-\mathrm{W}-\mathrm{Ti}-\mathrm{O}$ ceramics are presented in Figure 2. The specimens contain the $\mathrm{BaTi}_{4} \mathrm{O}_{9}$, $\mathrm{Ba}_{2} \mathrm{Ti}_{9} \mathrm{O}_{20}$, and $\mathrm{BaWO}_{4}$ phases (Table 1). According to the phase diagram of refractory oxides $\mathrm{BaO}-\mathrm{TiO}$, the specimens annealed at temperatures above $1623 \mathrm{~K}$ are characterized by a combination of $\mathrm{BaTi}_{4} \mathrm{O}_{9}$ and $\mathrm{Ba}_{2} \mathrm{Ti}_{9} \mathrm{O}_{20}$ compounds [20]. In all the specimens, except 3 , one can observe a segnetoelectrical phase $\mathrm{WO}_{3}$ whose lattice parameter $(a=0.3837 \mathrm{~nm})$ is typical of a film structure. At the maximum values of compacting parameters (specimen 5), there appears a metastable phase $\mathrm{BaTi}_{2} \mathrm{O}_{5}$.

XRD is used to obtain the phase information in the bulk, while XPS mainly probes the grain interface [21].

3.1. X-Ray Photoelectron Spectroscopy. According to the scanning electron microscopy (SEM) and atomic-force microscopy (AFM) data, the fracture in the specimens occurs at the grain boundaries; therefore, an analysis of the XPS spectra of the chip surface made it possible to define the composition of the ceramics interface regions. In the $W 4 f_{7 / 2}$ spectra (Table 2) one line corresponding to $\mathrm{W}^{6+}$ is observed: tungsten may be present in the form of either $\mathrm{WO}_{3}$ or $\left(\mathrm{WO}_{4}\right)^{2-}[22]$ which cannot be distinguished. In the Ti2 $p_{3 / 2}$ spectra the line of energy $458.6 \div 458.8 \mathrm{eV}$ corresponding to $\mathrm{Ti}^{4+}[23]$ is dominant practically in all specimens. $\mathrm{Ti}^{3+}$ is present only in specimen 5 obtained at $P=1050.4 \mathrm{MPa}$ and $W=3 \mathrm{~kW}$.

In the $B a 3 d_{5 / 2}$ spectra of the studied specimens three peaks corresponding to barium atoms in different chemical environments were detected: $E_{b} \mathrm{Ba}(\mathrm{I})=779.4 \pm 0.1 \mathrm{eV}$; $E_{b} \mathrm{Ba}(\mathrm{II})=780.5 \pm 0.1 \mathrm{eV} ; E_{b} \mathrm{Ba}(\mathrm{III})=781.5 \pm 0.1 \mathrm{eV}$.

In an XPS study of polycrystalline barium titanate $\left(\mathrm{BaTiO}_{3}\right)$ [24] the peak $\mathrm{Ba}(\mathrm{I})$ was attributed to barium atoms in perovskite-like structures. In the same paper much attention was given to interpretation of the $\mathrm{Ba}(\mathrm{I})$ peak which may be ascribed to barium in the $\mathrm{Ba}(\mathrm{OH})_{2}$ and 
TABLE 1: Compacting parameters (compacting pressure $P$, US power $W$ ), density $\rho$, and phase composition according to X-ray diffraction analysis of the studied specimens of $\mathrm{BaTiO}_{3}-\mathrm{WTiO}_{3}$ ceramics.

\begin{tabular}{|c|c|c|c|c|c|c|c|c|}
\hline Specimen & $P, \mathrm{MPa}$ & $W, \mathrm{~kW}$ & $\rho, \mathrm{g} / \mathrm{cm}^{3}$ & $\begin{array}{c}\mathrm{BaTi}_{4} \mathrm{O}_{9} \text {, mass } \\
(\%)\end{array}$ & $\begin{array}{c}\mathrm{Ba}_{2} \mathrm{Ti}_{9} \mathrm{O}_{20}, \text { mass } \\
(\%)\end{array}$ & $\begin{array}{c}\mathrm{BaWO}_{4} \text {, mass } \\
(\%)\end{array}$ & $\begin{array}{c}\mathrm{WO}_{3} \text {, mass } \\
(\%)\end{array}$ & $\begin{array}{c}\mathrm{BaTi}_{2} \mathrm{O}_{5} \text {, mass } \\
(\%)\end{array}$ \\
\hline 1 & 113.0 & 0 & 4.43 & 28 & 69 & 2 & 1 & - \\
\hline 2 & 525.0 & 0 & 4.48 & 28 & 63 & 8 & 1 & - \\
\hline 3 & 700.3 & 0 & 4.48 & 51 & 39 & 10 & - & - \\
\hline 4 & 1050.4 & 0 & 4.45 & 39 & 49 & 10 & 2 & - \\
\hline 5 & 1050.4 & 3.0 & 4.41 & 22 & 63 & 7 & 2 & 6 \\
\hline 6 & 874.4 & 1.5 & 4.52 & 46 & 44 & 9 & 1 & - \\
\hline
\end{tabular}

TABLE 2: Binding energy and relative content of Ti, Ba, and W in XPS spectra.

\begin{tabular}{|c|c|c|c|c|c|c|}
\hline \multirow{2}{*}{ Specimen } & \multicolumn{2}{|r|}{$\mathrm{Ti} 2 p_{3 / 2}$} & \multicolumn{2}{|c|}{$B a 3 d_{5 / 2}$} & \multicolumn{2}{|c|}{$W 4 f_{7 / 2}$} \\
\hline & $E_{b}, \mathrm{eV}$ & Relative content (\%) & $E_{b}, \mathrm{eV}$ & Relative content (\%) & $E_{b}, \mathrm{eV}$ & Relative content (\%) \\
\hline \multirow{2}{*}{1} & \multirow{2}{*}{458.8} & \multirow{2}{*}{100} & 779.4 & 13 & \multirow{2}{*}{36.6} & \multirow{2}{*}{100} \\
\hline & & & 781.4 & 87 & & \\
\hline \multirow{2}{*}{2} & \multirow{2}{*}{458.6} & \multirow{2}{*}{100} & 780.6 & 40 & \multirow{2}{*}{36.6} & \multirow{2}{*}{100} \\
\hline & & & 781.6 & 60 & & \\
\hline \multirow{2}{*}{3} & \multirow{2}{*}{458.8} & \multirow{2}{*}{100} & 780.4 & 13 & \multirow{2}{*}{36.6} & \multirow{2}{*}{100} \\
\hline & & & 781.4 & 87 & & \\
\hline 4 & 458.6 & 100 & 781.6 & 100 & 36.6 & 100 \\
\hline \multirow{2}{*}{5} & 458.0 & 22 & \multirow{2}{*}{789.8} & \multirow{2}{*}{100} & \multirow{2}{*}{36.6} & \multirow{2}{*}{100} \\
\hline & 459.0 & 88 & & & & \\
\hline 6 & 458.8 & 100 & 781.2 & 100 & 36.6 & 100 \\
\hline
\end{tabular}

TABle 3: The Ti: Ba: $\mathrm{W}$ ratio (at.\%) in the bulk (XRD data) and interface regions (XPS) of the ceramics investigated.

\begin{tabular}{lcc}
\hline Specimen & Method & Ti: Ba: W \\
\hline \multirow{2}{*}{1} & XRD & $94.0: 22.0: 1$ \\
& XPS & $7.1: 2.7: 1$ \\
2 & XRD & $31.0: 8.0: 1$ \\
& XPS & $7.5: 2.2: 1$ \\
3 & XRD & $30.0: 8.0: 1$ \\
& XPS & $6.0: 2.5: 1$ \\
4 & XRD & $23.0: 6.0: 1$ \\
& XPS & $5.3: 1.8: 1$ \\
5 & XRD & $38.0: 10.0: 1$ \\
& XPS & $5.3: 2.8: 1$ \\
6 & XRD & $30.0: 8.0: 1$ \\
& XPS & $6.6: 1.3: 1$ \\
\hline
\end{tabular}

$\mathrm{BaCO}_{3}$ compounds. Such an interpretation, however, takes no account of the analysis of the $\mathrm{C} 1 \mathrm{~s}$ and $\mathrm{O} 1 \mathrm{~s}$ spectra. In the case of the $\mathrm{BaCO}_{3}$ formation in the $\mathrm{Cl}$ s spectrum a component with binding energy $(289.4 \div 290.8) \mathrm{eV}$ should be observed [22]. The $\mathrm{Ba}(\mathrm{II})$ peak is also attributed [23] to $\mathrm{Ba}$ atoms in perovskite structures.

It is known that changes in the element-oxygen interatomic distance result in a shift of the element and oxygen XPS spectral lines. So, it was shown [25] that different structural constituents of vitreous silicium dioxide differ in the position of $\mathrm{O} 1 \mathrm{~s}$ and Si2p peaks: a $0.004 \mathrm{~nm}$ change in the Si-O distance results in the shift of the O1s peak by $0.3 \mathrm{eV}$ and Si2p by $0.3-0.9 \mathrm{eV}$. An analogous situation is apparently observed for the $\mathrm{Ba}(\mathrm{I})$ and $\mathrm{Ba}(\mathrm{II})$ structures. Both structures are perovskite-like but distorted and differ in the $\mathrm{Ba}-\mathrm{O}$ interatomic distance.

The available data for the $E_{b}$ value of $\mathrm{Ba} 3 \mathrm{~d}$ in the $\mathrm{BaTiO}_{3}$ perovskite structure substantially differ in magnitude: 778.5 , $780 \mathrm{eV} \mathrm{[23],} 789 \mathrm{eV}$ [12], $780.0 \mathrm{eV} \mathrm{[26],} \mathrm{and} 778.8 \mathrm{eV}$ [22]. This difference may be caused by distortions in the perovskite structure, all the structures being perovskite-like.

The position of the $\mathrm{Ba} 3 \mathrm{~d}$ peak (line) of (in) $\mathrm{BaCO}_{3}$ corresponds to $E_{b}$ of 779.8 [22] -780.0 эВ [26] Положение Ва3d линии $\mathrm{BaCO}_{3}$ соответствует $E_{b} 779.8$ [22] -780.0 [26] эB.

The position of the O1s oxygen peak of barium hydroxide $(531.2 \mathrm{eV})$ coincides with the position of the peak of $\mathrm{O}$ atoms included in oxygen-containing organic functional groups $(\mathrm{C}-\mathrm{O})$ which are present in the adsorbed hydrocarbon layer on the chip surface. Therefore, an analysis of the Ba3d and O1s XPS spectra cannot provide an unambiguous answer to the question of the barium hydroxide presence on the surface of the ceramic chips under study.

According to the $\mathrm{X}$-ray phase analysis, the ceramics investigated include some compounds of perovskite-like structure: $\mathrm{BaTi}_{4} \mathrm{O}_{9}$ and $\mathrm{Ba}_{2} \mathrm{Ti}_{9} \mathrm{O}_{20}$ (Table 3). In order to determine to what exactly barium compound correspond the $\mathrm{Ba}(\mathrm{I})$ and $\mathrm{Ba}(\mathrm{II})$ peaks, one should study the standard specimens of barium titanates. 

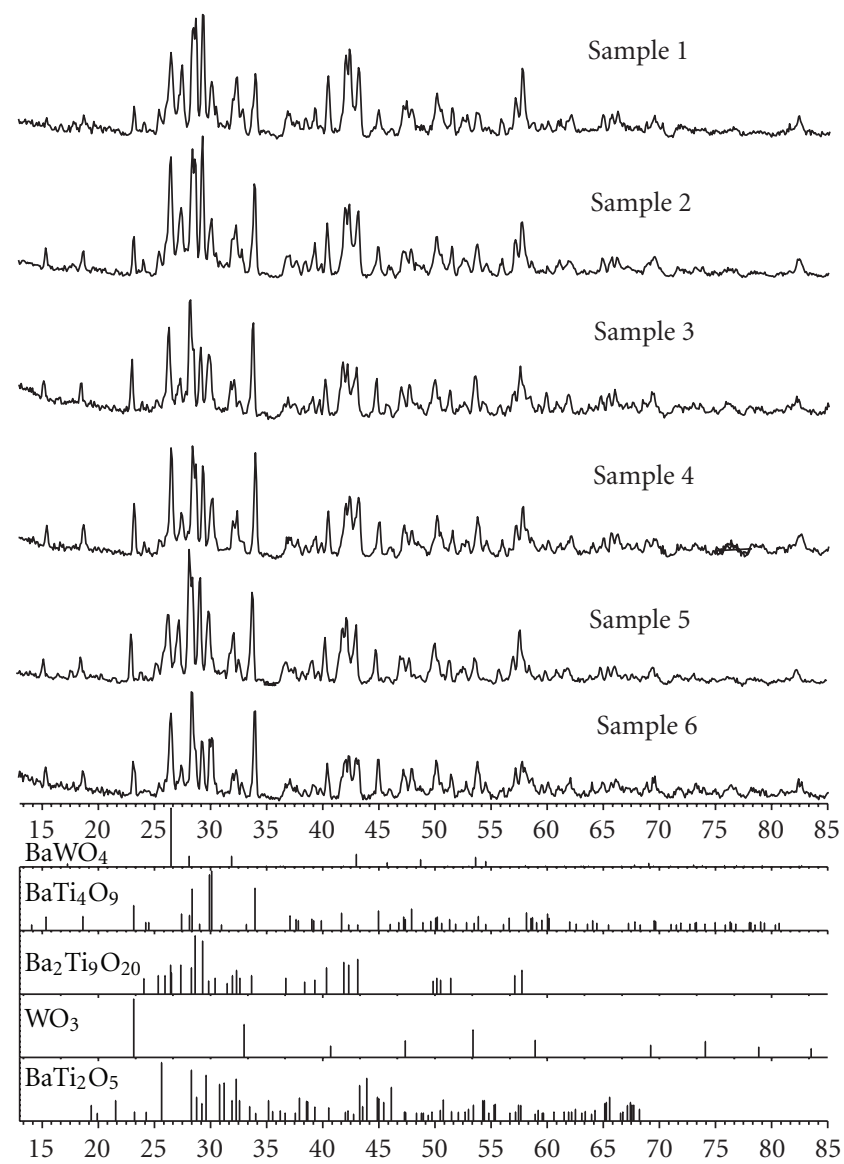

FIgURE 2: Specimen diffractograms.

The Ba3d peak with binding energy $781.5 \mathrm{eV}$, lacking in the XPS spectra of the samples investigated in [22], may be attributed to $\mathrm{Ba}$ atoms included in a structure other than perovskite. So, two perovskite-like structures (I and II) that probably differ in composition are present on the chip surface. The structure I is observed only in specimens 1 and 5, while the structure II appears with increasing compacting pressure to $525 \mathrm{MPa}$ in specimen 2, decreases with pressure in specimen 3 , and disappears in specimens 4 and 6. The structure III is a compound other than perovskite. In specimens $1 \rightarrow 3 \rightarrow 4,6$ its content increases from $\sim 60 \%$ to $\sim 100 \%$.

The Ba: Ti: W ratio (at.\%) in the bulk, obtained from the $\mathrm{X}$-ray phase analysis, is presented in Table 3 in comparison with that in the interface regions (XPS data). The difference in elemental composition between the bulk and the interface regions is due, in particular, to an increase in the content of tungsten which diffuses during sintering into the grainsurface areas by the action of temperature.

The titanium and barium content diminishes, the decrease in the number of $\mathrm{Ti}$ atoms being greater, as seen from the $\mathrm{Ba}$ : Ti ratio.

With increasing compacting pressure the tungsten content grows on the chip surface of sintered specimens. The structure III is likely to correspond to scheelite $\mathrm{BaWO}_{4}$ whose amount in the interface region may increase as the $\mathrm{Ba}$ and $\mathrm{W}$ fractions grow. The line $781.5 \mathrm{eV}$ corresponds to a metastable modification of barium titanate arising only in interface regions. Since the layer analyzed by the XPS method is several nanometers thick, this metastable modification may exist as a film phase. Moreover, such a considerable difference in $\mathrm{W}$ concentration between the grain surface and the bulk confirms the assumption that $\mathrm{WO}_{3}$ forms only in the interface regions. As the content of the perovskitelike structure in the interface regions decreases and then completely disappears with increasing pressure, one can suppose that the acoustic transmission of the boundaries must grow as a consequence of the decrease in structure imperfection of the interface regions.

3.2. Phonon Spectroscopy. The experimental technique and the analysis of propagation of nonequilibrium phonons in ceramic materials were reported in [17]. In this study, the samples were plane-parallel polished plates with a thickness (L) $0.1-1.0 \mathrm{~mm}$ and an area of about $0.5 \mathrm{~cm}^{2}$. The phonon injector (gold) and detector (tin) films were formed on the opposite faces of the samples by thermal deposition in vacuum. Experiments were performed in liquid helium in the temperature range $1.5-3.8 \mathrm{~K}$. The thermostat temperature was varied by pumping off helium vapor. The temperature measurement accuracy was no worse than $10^{-3} \mathrm{~K}$. The operating point of the bolometer was shifted by applying a weak magnetic field. The experimentally measured value was the time $t_{m}$ of arrival of the maximum diffusion signal of nonequilibrium phonons at the detector (bolometer). Phonons were injected from the metal film located on the opposite face of the sample and heated by a short $\left(10^{-7} \mathrm{~s}\right)$ current pulse to a temperature $T_{h} ; \Delta T=T_{h}-T_{0} \ll T_{0}$ ( $T_{0}$ is the thermostat temperature). This approach made it possible, providing $T_{h} \approx T_{0}$ and changing the thermostat temperature, to obtain the temperature dependence $t_{m}(T)$.

The diffusion mode was controlled by the corresponding dependence of $t_{m}$ on the specimen thickness: $t_{m}(L) \sim L^{2}$.

The experimentally measured time of the phonon nonequilibrium diffusion signal maximum, $t_{m}(T)$, is definitely related to the effective diffusion coefficient $D_{\text {eff }}(T)$ by the transport mean free path $l_{\text {tr }}$ of nonequilibrium phonons of frequency $\omega \cong 2,8 \mathrm{kT} / \mathrm{h}[17]$

$$
D_{\text {eff }}(T)=\frac{L^{2}}{2 t_{m}(T)}=\frac{1}{3 l_{\mathrm{tr}}(T) v},
$$

where $L$ is the specimen size in the NP flow direction; $v$ is the average sound velocity (in the ceramics under study $v=4.54 \cdot 10^{5} \mathrm{~cm} / \mathrm{s}$ ); $T$ is the NP temperature. A comparison between the experimental temperature dependences of the NP scattering and theory was performed by the relation [27]

$$
l_{\mathrm{tr}}=l_{0} \cdot \frac{f_{\omega}}{1-f_{\omega}},
$$

where $f_{\omega}$ is the probability of the nonequilibrium phonon passage through the grain boundary [18]; $l_{0} \approx 0,6 R$ is the mean ballistic path of NP in a single grain of size $R$. 
TABLE 4: Characteristics of the nanoceramics under study*.

\begin{tabular}{|c|c|c|c|c|c|c|}
\hline Specimen & $R_{\mathrm{ag}}, \mathrm{nm}$ & $R_{\mathrm{gr}}, \mathrm{nm}$ & $\mathrm{CSA}, \mathrm{nm}$ & $D$ at $3.8 \mathrm{~K}$ & $l_{\mathrm{gb}}, \mathrm{nm}$ & $\rho_{2} v_{2} / \rho_{1} v_{1}$ \\
\hline 1 & 2010 & 250 & 86 & 39.00 & 1.50 & 0.70 \\
\hline 2 & 1830 & 273 & 90 & 8.07 & 1.50 & 0.80 \\
\hline 3 & 1747 & 232 & 96 & 52.00 & 1.28 & 0.85 \\
\hline 4 & 1414 & 236 & 150 & 29.50 & 0.27 & 0.60 \\
\hline 5 & 2037 & 260 & 150 & 57.00 & 0.35 & 0.70 \\
\hline 6 & 1711 & 263 & 148 & 70.50 & 1.10 & 0.85 \\
\hline
\end{tabular}

${ }^{*} R_{\mathrm{ag}}$ is the agglomerate size; $R_{\mathrm{gr}}$ is the grain size; $R_{\mathrm{CSA}}$ are coherent scattering areas in the specimens according to the XPS, AFM, and SEM data; $D$ is the effective diffusion coefficient; $l_{\mathrm{gb}}$ is the interface region thickness; $\rho_{2} v_{2} / \rho_{1} v_{1}$ is the acoustic impedance.

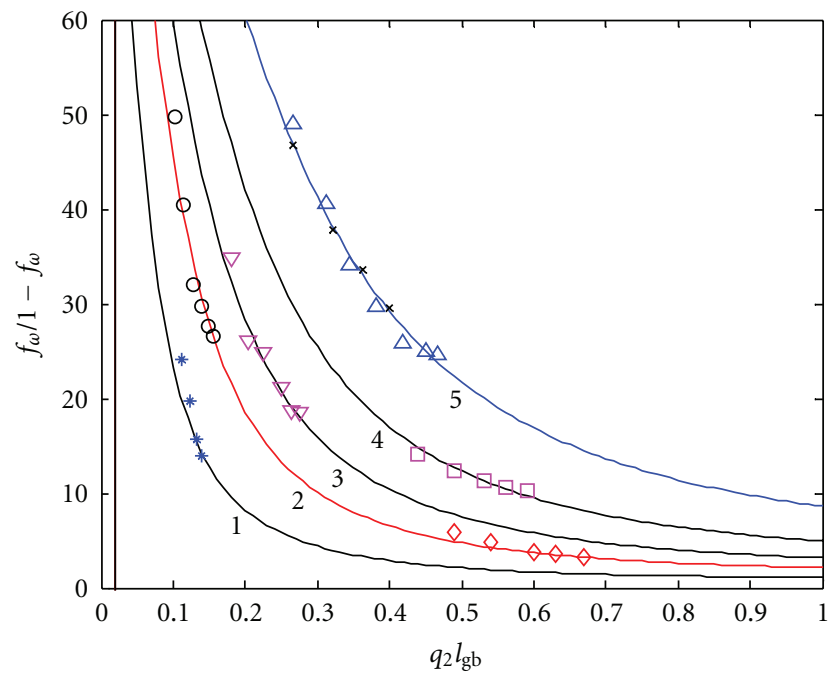

FIGURE 3: The probability $f_{\omega} /\left(1-f_{\omega}\right)$ of the NP flow passing through the plane intergranular boundary of thickness $l_{\mathrm{gb}}$ as a function of $q_{2} l_{\mathrm{gb}}$. (1) $\rho_{2} v_{2} / \rho_{1} v_{1}=0.6$; (2) 0.7 ; (3) 0.75 ; (4) 0.8 ; (5) 0.85 . The experimental points for specimens: $1(\diamond) ; 2(\square) ; 3(\triangle) ; 4(*) ; 5$ $(\bigcirc) ; 6(\times)$, and a specimen prepared with a different procedure $(\nabla)$.

Figure 3 presents a set of theoretical curves of $f_{\omega} /\left(1-f_{\omega}\right)$ as a function of $q_{2} l_{\mathrm{gb}}$ calculated for different ratios between the acoustic impedances of the grain material, $\rho_{1} v_{1}$, and intergranular layer, $\rho_{2} v_{2} ; l_{\mathrm{gb}}$ is the layer thickness, and $q_{1,2}$ are the wave vectors of a phonon of frequency $\omega$ in the grain material and intergranular layer, respectively:

$$
\begin{gathered}
q_{1}=\frac{2.8 k T}{\hbar v_{1}}, \\
q_{2}=\frac{q_{1}}{\rho_{2} v_{2} / \rho_{1} v_{1}} .
\end{gathered}
$$

For each specimen the experimental values of temperature dependences $l_{\mathrm{tr}}(T) / 0,6 R$ were fitted to a theoretical curve. In the case of a good fit of the experimental dependence to the theoretical curve (corresponding to a particular value of $\left.\rho_{2} v_{2} / \rho_{1} v_{1}\right)$ the thickness $l_{\mathrm{gb}}$ was determined. The $l_{\mathrm{gb}}$ value for each specimen and the corresponding parameters $\rho_{2} v_{2} / \rho_{1} v_{1}$ are presented in Table 4.

In the ceramics studied different boundary types are observed: boundaries between agglomerates, between grains in the agglomerates, and boundaries between areas of coherent scattering. However, a satisfactory agreement between the theoretical calculations and the experimental temperature dependences of NP scattering is observed only in the case when $R$ is the size of grains (particles) forming the agglomerates. Indirect evidence on the efficiency of NP scattering at different boundaries in ceramics may be provided by the value of the $l_{\mathrm{tr}} / R$ ratio. So, for specimen 4 at $T=3.8 \mathrm{~K}$ this ratio is 1.4 for agglomerates, 8 for grains, $15-$ 30 for CSA, and it increases as the NP temperature (energy) decreases. It may appear that the main contribution to the NP scattering should come from the agglomerate boundaries, but then, because of the large boundary thickness, the experimental NP scattering dependences would lie on the wings of the theoretical curves and exhibit a weaker dependence of $l_{\mathrm{gb}}(T) / d$ on $q_{2} l_{\mathrm{gb}}$ (temperature). This is not the case because the intergranular boundaries greatly exceed the boundaries between agglomerates in number, and it may be concluded that the temperature dependence of the NP scattering is determined by the scattering at boundaries between the grains forming the agglomerates.

Consider now the results presented in Figure 3. The experimental points obtained for specimens 1 and 5 lie on the same curve (i.e., are characterized by the same impedance), which corroborates the XPS evidence for the existence, in interface regions, of the structure $\mathrm{Ba}(\mathrm{I})$ being characteristic of these specimens only. The difference between them in temperature dependence $D(T)$ suggests that in specimen 5 the thickness of the interface region diminishes and its hardness (i.e., impedance) grows as a result of an increase in the content of cubic phase $\mathrm{WO}_{3}$. The difference in the interface region structure revealed by XPS in specimens 4 and 5 compacted at a pressure $P=1040.5 \mathrm{MPa}$ and different power of ultrasonic activation is also confirmed by the phonon spectroscopy data. Specimens 1 and 2 compacted at low pressures without US action are distinguished by a large boundary thickness. The optimum boundary structure is found in specimens compacted at a pressure of about 700$800 \mathrm{MPa}$ which allows the formation of an interface region with prevailing content of isotropic structure.

\section{Conclusion}

In the studied segnetoelectrical Ba-W-Ti-O ceramics, compacted under different conditions of pressure and ultrasound 
action with subsequent sintering at $1623 \mathrm{~K}$, the ceramic phase composition, as well as the structure and composition of the interface regions, varies in a nonmonotonic way. It is shown that the interface region composition substantially differs from that of the grain bulk owing to the diffusion of tungsten atoms to the grain surface during sintering. Increasing the compacting pressure is favorable to the retention of the $\mathrm{BaWO}_{4}$ phase in the bulk of a specimen. Increasing the pressure during dry static compacting and exposure to ultrasound result in the formation of a complex structure of fragments and boundaries between them, increase the acoustic density, and lead to a decrease in the intergranular boundary thickness to the values that are sometimes comparable to the lattice constant of the boundary material. The boundary structure becomes optimum at a pressure of about 700-800 MPa, which is due to a decrease in the perovskite structure content in the interface regions.

\section{Acknowledgments}

This work was supported by the RFBR Grant no. 11-0200704, Russian Ministry of Science and Education (contract no. 13.G25.31.0021; state assignment "Science").O. Khasanov is thankful to Dr. S. A. Fomin for useful discussions.

\section{References}

[1] B. M. Kulwicki, “Ceramic sensors and transducers," Journal of Physics and Chemistry of Solids, vol. 45, no. 10, pp. 1015-1031, 1984.

[2] K. Unchino and T. Takasu, "Property variation of piezoelectric ceramics with microstructure," Inspection, vol. 10, pp. 29-34, 1986.

[3] B. D. Begg, E. R. Vance, and J. Nowotny, "Effect of particle size on the room-temperature crystal structure of barium titanate," Journal of the American Ceramic Society, vol. 77, no. 12, pp. 3186-3192, 1994.

[4] M. B. Park, N. H. Cho, C. D. Kim, and S. K. Lee, "Phase transition and physical characteristics of nanograined $\mathrm{BaTiO}_{3}$ ceramics synthesized from surface-coated nanopowders," Journal of the American Ceramic Society, vol. 87, no. 3, pp. 510512, 2004

[5] T. Yamamoto and T. Sakuma, "Abnormal grain growth of $\mathrm{BaTiO}_{3}$ with small cation nonstoichiometry," Materials Science Forum, vol. 204-206, pp. 491-496, 1996.

[6] T. Yamamoto, Y. Ikuhara, K. Hayashi, and T. Sakuma, "Grain boundary structure in $\mathrm{TiO}_{2}$-excess barium titanate," Journal of Materials Research, vol. 13, no. 12, pp. 3449-3452, 1998.

[7] V. V. Ivanov, S. N. Ivanov, O. V. Karban, A. V. Taranov, E. N. Khazanov, and V. R. Khrustov, "Structure of nanocrystalline titania ceramics studied by X-ray diffraction, atomic force microscopy, and thermal phonon kinetics," Inorganic Materials, vol. 40, no. 11, pp. 1233-1238, 2004.

[8] O. V. Karban, O. L. Khasanov, and O. M. Kanunnikova, "Microstructure of $\mathrm{ZrO}_{2}$ nanoceramics," Journal of Structural Chemistry, vol. 45, pp. S147-S153, 2004.

[9] K. Matsui, H. Horikoshi, N. Ohmichi, M. Ohgai, H. Yoshida, and Y. Ikuhara, "Cubic-formation and grain-growth mechanisms in tetragonal zirconia polycrystal," Journal of the American Ceramic Society, vol. 86, no. 8, pp. 1401-1408, 2003.
[10] T. Takeuchi, K. Ado, T. Asai et al., "Thickness of cubic surface phase on barium titanate single-crystalline grains," Journal of the American Ceramic Society, vol. 77, no. 6, pp. 1665-1668, 1994.

[11] C. Miot, E. Husson, C. Proust, R. Erre, and J. P. Coutures, "Residial carbon evolution in $\mathrm{BaTiO}_{3}$ ceramics studies by XPS after ion etching," Journal of the European Ceramic Society, vol. 18, no. 4, pp. 339-343, 1998.

[12] M. Wegmann, L. Watson, and A. Hendry, "XPS Analysis of submicrometer barium titanate powder," Journal of the American Ceramic Society, vol. 87, no. 3, pp. 371-377, 2004.

[13] O. Khasanov, E. Dvilis, V. Sokolov, and Yu. M. Pokholkov, "Mechanisms of dry powder net-shaping under ultrasonic vibration and by the collector method," in Proceedings of the 2nd International Congress on Ceramics, pp. 359-368, Verona, Italy, 2008.

[14] V. I. Nefedov, X-ray Photoelectron Spectroscopy of Inorganic Materials, Chimia, Moscow, Russia, 1984.

[15] V. I. Povstugar, A. A. Shakov, S. S. Mikhailov, E. V. Voronina, and E. P. Elsukov, "Resolution of complex X-ray photoelectron spectra using fast discrete fourier transformation with improved convergence procedure: assessment of the usability of the procedure," Journal of Analytical Chemistry, vol. 53, no. 8, pp. 697-700, 1998.

[16] S. N. Ivanov, A. G. Kozorezov, and A. V. Taranov, "Nonequilibrium acoustic phonons in nanocrystalline ceramics," Journal of Experimental and Theoretical Physics, vol. 75, pp. 319-328, 1992.

[17] Y. N. Barabanenkov, V. V. Ivanov, S. N. Ivanov, A. V. Taranov, and E. N. Khazanov, "Investigation of nanoceramics based on aluminum and zirconium oxides using the heat pulse method," Journal of Experimental and Theoretical Physics, vol. 92, no. 3, pp. 474-479, 2001.

[18] Y. N. Barabanenkov, V. V. Ivanov, S. N. Ivanov et al., "Propagation of phonons in nanocrystalline $\mathrm{ZrO}_{2}: \mathrm{Y}_{2} \mathrm{O}_{3}$ ceramics," Journal of Experimental and Theoretical Physics, vol. 102, no. 1, pp. 114-120, 2006.

[19] O. Khasanov, E. Dvilis, V. Sokolov, Y. Pokholkov, and G. Loutts, "Nanopowder net-shaping for manufacturing nanostructured ceramics," in Proceedings of the Nanotechnology Conference and Trade Show (NSTI '06), pp. 23-26, Boston, Mass, USA, May 2006.

[20] W. Wong-Ng, R. S. Roth, T. A. Vanderah, and H. F. McMurdie, "Phase equilibria and crystallography of ceramic oxides," Journal of Research of the National Institute of Standards and Technology, vol. 106, no. 6, pp. 1097-1134, 2001.

[21] D. Briggs and M. P. Seach, Practical Surface Analysis by Auger and X-ray Photoelectron Spectroscopy, Division of Materials Applications, National Physical Laboratory, John Wiley \& Sons, Teddington, Middlesex, UK, 1983.

[22] NIST, http://www.nist.gov/srd/.

[23] S. Kumar, V. S. Raju, and T. R. N. Kutty, "Investigations on the chemical states of sintered barium titanate by X-ray photoelectron spectroscopy," Applied Surface Science, vol. 206, no. 1-4, pp. 250-261, 2003.

[24] S. A. Nasser, "X-ray photoelectron spectroscopy study on the composition and structure of $\mathrm{BaTiO}_{3}$ thin films deposited on silicon," Applied Surface Science, vol. 157, no. 1, pp. 14-22, 2000.

[25] O. Kanunnikova, "X-Ray photoelectron spectroscopy applied to atomic structure analysis of silicate glasses thin layers," in $X$-ray Photoelectron Spectroscopy, J. Wagner, Ed., Nova Science, 2009. 
[26] http://www.lasurface.com/database/spectreXPS.php.

[27] V. D. Kagan and A. V. Suslov, "Effect of an electric field on heat-pulse propagation in $\mathrm{SrTiO}_{3}$," Physics of the Solid State, vol. 9, pp. 1457-1464, 1994. 

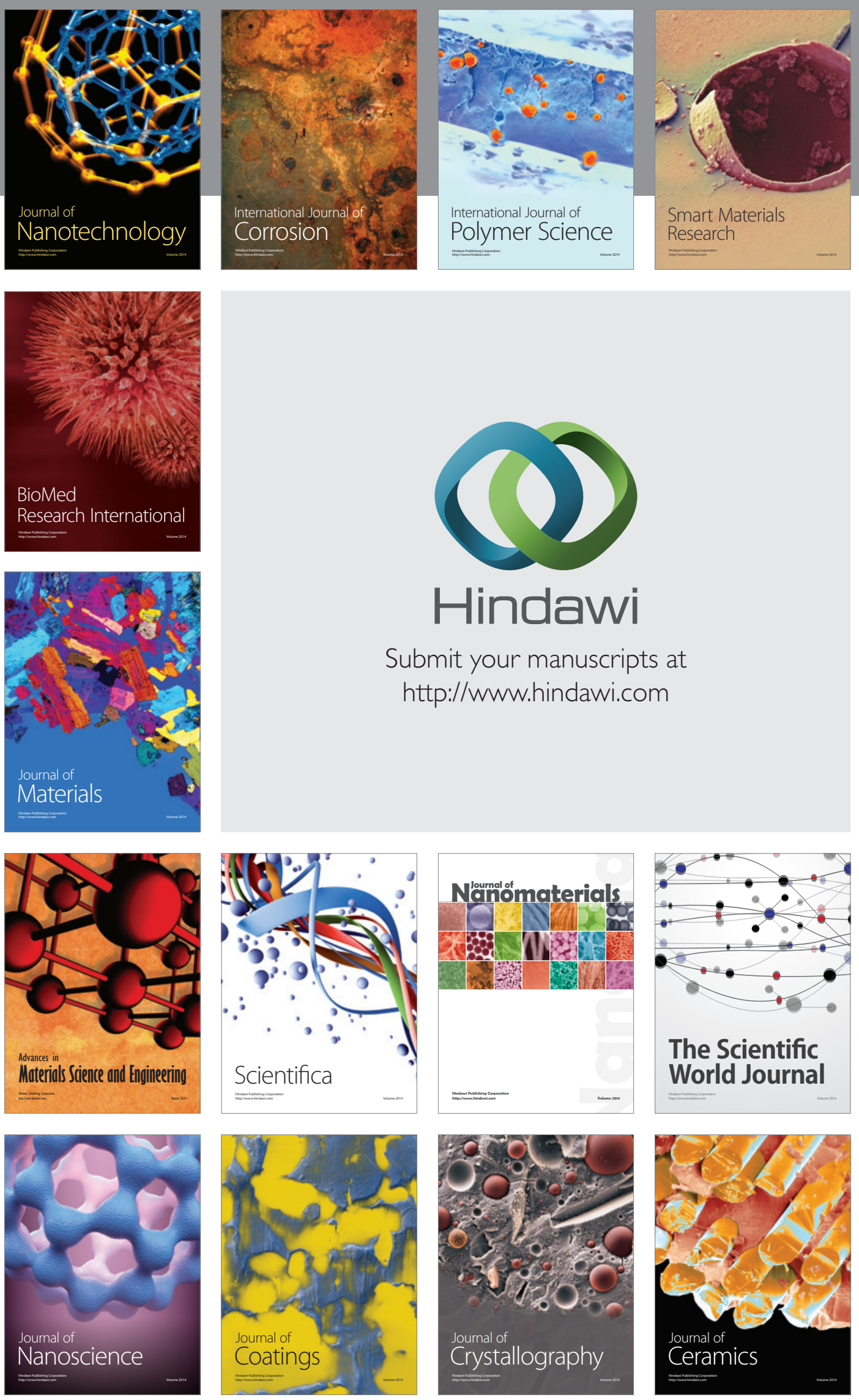

The Scientific World Journal

Submit your manuscripts at

http://www.hindawi.com

\section{World Journal}

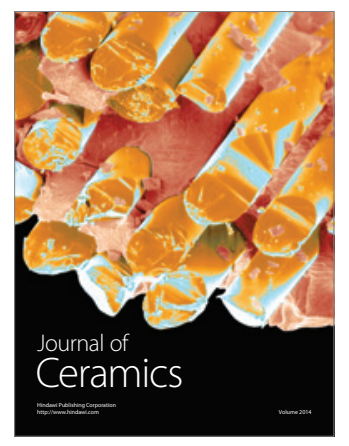

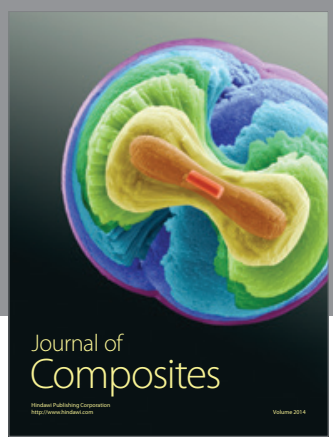
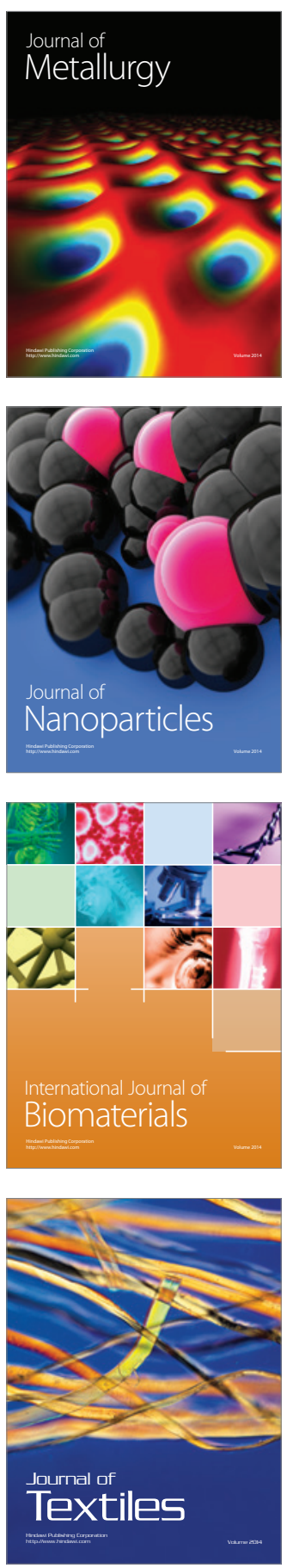